\title{
Observational Studies of Atmospheric Aerosols over Bozeman, Montana, Using a Two-Color Lidar, a Water Vapor DIAL, a Solar Radiometer, and a Ground-Based Nephelometer over a 24-h Period
}

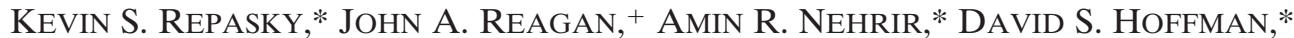 \\ Michael J. Thomas,* John L. Carlsten, " Joseph A. Shaw,* And Glenn E. Shaw ${ }^{\circledR}$ \\ * Department of Electrical and Computer Engineering, Montana State University, Bozeman, Montana \\ ${ }^{+}$Department of Electrical and Computer Engineering, The University of Arizona, Tucson, Arizona \\ \# Department of Physics, Montana State University, Bozeman, Montana \\ ${ }^{\circledR}$ Geophysical Institute, University of Alaska Fairbanks, Fairbanks, Alaska
}

(Manuscript received 26 February 2010, in final form 24 June 2010)

\begin{abstract}
Coordinated observational data of atmospheric aerosols were collected over a 24-h period between 2300 mountain daylight time (MDT) on 27 August 2009 and 2300 MDT on 28 August 2009 at Bozeman, Montana $\left(45.66^{\circ} \mathrm{N}, 111.04^{\circ} \mathrm{W}\right.$, elevation $\left.1530 \mathrm{~m}\right)$ using a collocated two-color lidar, a diode-laser-based water vapor differential absorption lidar (DIAL), a solar radiometer, and a ground-based nephelometer. The optical properties and spatial distribution of the atmospheric aerosols were inferred from the observational data collected using the collocated instruments as part of a closure experiment under dry conditions with a relative humidity below $60 \%$. The aerosol lidar ratio and aerosol optical depth retrieved at 532 and $1064 \mathrm{~nm}$ using the two-color lidar and solar radiometer agreed with one another to within their individual uncertainties while the scattering component of the aerosol extinction measured using the nephelometer matched the scattering component of the aerosol extinction retrieved using the 532-nm channel of the two-color lidar and the singlescatter albedo retrieved using the solar radiometer. Using existing aerosol models developed with Aerosol Robotic Network (AERONET) data, a thin aerosol layer observed over Bozeman was most likely identified as smoke from forest fires burning in California; Washington; British Columbia, Canada; and northwestern Montana. The intrusion of the thin aerosol layer caused a change in the atmospheric radiative forcing by a factor of $1.8 \pm 0.5$ due to the aerosol direct effect.
\end{abstract}

\section{Introduction}

Aerosols play an important role in the radiative forcing of the climate system (Forster et al. 2007; Haywood and Boucher 2000). However, the diversity of aerosol species and their highly variable spatial and temporal distributions in the atmosphere make it difficult to understand the role aerosols play on the radiative forcing of the climate system. This has led the Intergovernmental Panel on Climate Change (IPCC) to state in the Fourth Assessment Report (FAR) that the radiative forcing associated with aerosols has a low level of scientific understanding (Forster et al. 2007).

Corresponding author address: Kevin S. Repasky, Dept. of Electrical and Computer Engineering, Cobleigh Hall, Rm. 610, Montana State University, Bozeman, MT 59717.

E-mail: repasky@ece.montana.edu
Long-term monitoring is needed to better understand the role of aerosols on the radiative forcing of the climate system (Delle Monache et al. 2004; Haywood et al. 2003; Schmid et al. 2009; Schmid et al. 2006). Monitoring of atmospheric aerosols under ambient atmospheric conditions should occur on the local to regional scales, due to the nonuniform aerosol spatial distribution, at a wide variety of geographic locations to encompass the diversity of aerosol species (Schmid et al. 2009; Schmid et al. 2006). Long-term studies of the vertical distribution of aerosols are being carried out using in situ (Delle Monache et al. 2004; Andrews et al. 2004; Sheridan et al. 2001) and remote sensing (Wulfmeyer and Feingold 2000; Kotchenruther et al. 1999; Ferrare et al. 2000; Schmid et al. 2003; Pahlow et al. 2006; Ismail et al. 2000) instruments with various deployment strategies. Satellite-based remote sensing instruments (the following Web pages provide additional information: http://modis.gsfc.nasa.gov, 
http://www.nasa.gov/mission_pages/calipso/main/index. html, and http://www.nasa.gov/mission_pages/cloudsat/ main/index.html) are providing aerosol studies on a global scale while networks of common instruments such as the solar radiometers deployed as part of the National Aeronautics and Space Administration's (NASA) Aerosol Robotic Network (AERONET) program (Holben et al. 2001) are providing aerosol data from worldwide sites using uniform data collection, calibration, and data processing techniques. Ground- and aircraft-based remote sensing instruments combined with in situ instruments are being deployed at field sites through programs such as the Atmospheric Radiation Measurement (ARM) program (Sheridan et al. 2001; Stokes and Schwartz 1994; Ackerman and Stokes 2003) or through multi-investigator field campaigns (Delle Monache et al. 2004; Haywood et al. 2003; Schmid et al. 2009; Schmid et al. 2003; Ismail et al. 2000; Ferrare et al. 2006; Johnson et al. 2009) to better understand the role of atmospheric aerosols on the radiative forcing of the climate system. Because of the spatial and temporal variations of atmospheric aerosols, small-scale, long-term studies of atmospheric aerosols from a variety of locations can complement these larger aerosol monitoring efforts.

In this paper, three ground-based remote sensing instruments and one ground-based in situ instrument are deployed to study aerosol optical properties for a 24-h period over Bozeman, Montana $\left(45.66^{\circ} \mathrm{N}, 111.04^{\circ} \mathrm{W}\right.$, elevation $1530 \mathrm{~m})$. The remote sensing instruments developed at Montana State University include an eye-safe diode-laser-based differential absorption lidar (DIAL) for water vapor profiling in the lower troposphere (Nehrir et al. 2009a,b) and a two-color backscatter lidar for aerosol profiling. A solar radiometer operated as part of the NASA-run AERONET program (Holben et al. 2001) was used for measuring and retrieving column-integrated aerosol optical properties and a ground-based nephelometer was deployed for measurements of the scattering component of the aerosol extinction. The deployment of this initial set of instruments represents the first step in the development of a remote sensing facility for atmospheric studies at Montana State University.

The deployment of multiple instruments allows for a closure experiment to be performed. Closure experiments (Schmid et al. 2003; Huebert et al. 2003) are important for verifying the consistency of retrieved aerosol optical properties using various instruments and have the potential to reduce the uncertainties associated with aerosol radiative forcing estimates. During this experiment, the aerosol lidar ratio, often referred to as simply the lidar ratio or the extinction to backscatter ratio $S_{a}$ and the aerosol optical depth retrieved using the two-color lidar are compared with the aerosol optical depth and lidar ratio retrieved using the solar radiometer. Furthermore, the scattering component of the aerosol extinction calculated using the single-scatter albedo retrieved with the solar radiometer and the total aerosol extinction retrieved using the two-color lidar is compared with the scattering component of the aerosol extinction measured using the ground-based nephelometer.

The ability to measure aerosol optical properties is important for understanding the effects of aerosols on the radiative forcing of the climate system. Furthermore, data from an AERONET site (Holben et al. 2001) located on the Montana State University campus in Bozeman have been used to classify aerosol species based on the columnintegrated aerosol optical properties (Omar et al. 2009; Omar et al. 2005; Reagan et al. 2004; Cattrall et al. 2005; Wang et al. 2005). The ability to classify aerosols into various species can be used to classify aerosols into natural and anthropogenic categories that can help in the understanding of the natural and anthropogenic radiative forcings resulting from the interaction of aerosols with incoming solar radiation and longwave thermal emission. Cattrall et al. (Reagan et al. 2004; Cattrall et al. 2005; Wang et al. 2005) used inversions from scanning solar radiometers at various AERONET sites to characterize aerosol optical properties at 550-nm and 1020 -nm wavelengths. The results of this grouping of aerosol optical properties led to the development of the constrained ratio aerosol model-fit (CRAM) technique for inversion of two-wavelength lidar data when other constraining information such as the total aerosol optical depth is not available. a similar study was carried out by Omar et al. (Omar et al. 2005, 2009) based on more than 143000 solar radiometer measurements from more than 250 AERONET sites using the inversion results for the 440-, 670-, 870-, and 1020-nm channels. The clustering algorithm used by Omar et al. (2005, 2009) resulted in six statistically significant clusters of aerosol optical properties. The retrieved aerosol optical properties using the set of four instruments are compared to these general aerosol models to classify a thin layer of smoke. Back-trajectory calculations of the air mass present over Bozeman on 28 August 2009 suggest this smoke originated from forest fires burning in California; Washington; British Columbia, Canada; and northwestern Montana.

This paper is organized as follows. A description of the two-color lidar and eye-safe diode-laser-based water vapor DIAL are presented in section 2. Observational data and an analysis are presented in section 3. In section 4, a discussion of the observational data and a comparison to the aerosol models developed from the AERONET sites are presented. Finally, some brief concluding remarks are presented in section 5 . 


\section{Instrumentation}

\section{a. Instrumentation introduction}

A set of four instruments was deployed for observational studies of atmospheric aerosols during 27-28 August 2009. The first two instruments included a two-color backscatter lidar for the profiling of atmospheric aerosols and a DIAL for profiling water vapor in the lower troposphere (Nehrir et al. 2009a,b). These two instruments were developed at Montana State University and are described below. The remaining instruments included a ground-based Cimel 318 sun-sky-scanning solar radiometer operated as part of the AERONET program (Holben et al. 2001) and a ground-based nephelometer provided on loan from the University of Alaska at Fairbanks.

\section{b. Two-color lidar}

An Nd:YAG laser is used to produce light at the fundamental 1064-nm and second harmonic 532-nm wavelengths for the two-color lidar. The operating parameters for this instrument are summarized in Table 1. The flashlamp-pumped Q-switched laser produces laser pulses of approximately $9.9 \mathrm{~ns}$ with a pulse repetition frequency (PRF) of $20 \mathrm{~Hz}$. The pulse energy at the fundamental (second harmonic) wavelength is $50 \mathrm{~mJ}(100 \mathrm{~mJ})$. The beams exit the laser head collinearly with a beam diameter of $0.54 \mathrm{~cm}$. The two beams are next expanded and recollimated using a $5 \times$ telescope in order to minimize the divergence of the transmitter. After the second lens, the collimated light has a beam diameter of $2.7 \mathrm{~cm}$. The collimated light is next incident on a dielectric mirror that directs most of the collinear fundamental and second harmonic light into the atmosphere. The small amount of the fundamental and second harmonic light passing through this dielectric mirror is then separated and directed onto energy detectors used to monitor the pulse energy at both the 532- and 1064-nm wavelengths.

The optical receiver for the two-color lidar instrument uses a 28-cm-diameter Schmidt-Cassegrain telescope to collect the light scattered by the atmosphere. An iris is placed at the focal plane of the telescope and is used to reduce the field of view of the telescope to $2 \mathrm{mrad}$, approximately 3 times larger than the 0.65 -mrad divergence angle of the beams leaving the laser transmitter. Light passing through the iris is next split using a dielectric mirror with the 532-nm light directed to a gated photomultiplier tube (PMT) and the 1064-nm light directed to an avalanche photodiode (APD). The laser transmitter comes into full overlap with the optical receiver at $750 \mathrm{~m}$.

Calibration of the lidar instrument is necessary to ensure that an inversion performed on the lidar return data accurately reflects the aerosol optical properties.
TABLE 1. Operating parameters for the two-color backscatter lidar.

\begin{tabular}{ll}
\hline \multicolumn{1}{c}{ Parameters } & Measured values \\
\hline Operating wavelengths & $532 \mathrm{and} 1064 \mathrm{~nm}$ \\
Pulse duration & $9.9 \mathrm{~ns}$ \\
PRF & $20 \mathrm{~Hz}$ \\
Pulse energy 532-nm channel & $50 \mathrm{~mJ}$ \\
Pulse energy 1064-nm channel & $100 \mathrm{~mJ}$ \\
Telescope diameter & $28 \mathrm{~cm}$ \\
Receiver FOV & $2 \mathrm{mrad}$ \\
\hline
\end{tabular}

The 532-nm channel of the lidar is calibrated using data collected from the free troposphere where molecular scattering dominates the return signal. The 532-nm calibration constant is found by comparing the modeled Rayleigh scattering (Kovalev and Eichinger 2004) with the range-corrected return signal collected by the twocolor lidar. There is not enough molecular backscatter at $1064 \mathrm{~nm}$ to directly calibrate the 1064-nm channel of the lidar. The calibration of the 532-nm channel is transferred to the 1064-nm channel using scattered light from cirrus clouds at each wavelength (Reagan et al. 2002). The lidar calibration constant for the 532-nm channel is calculated for each inversion in the time series. The 1064-nm calibration constant calculated using scattering from cirrus clouds is monitored when the atmospheric conditions permit. Due to the lack of cirrus clouds, the 1064-nm channel calibration constant was assumed to be constant throughout the duration of the measurement.

\section{c. Water vapor differential absorption lidar (DIAL)}

The water vapor DIAL instrument developed at Montana State University (Nehrir et al. 2009a,b) uses a tunable external cavity diode laser (ECDL) operating in the Littman-Metcalf configuration capable of accessing water vapor absorption bands in the 824-841-nm spectral region. The tunable ECDL serves as a master oscillator for the master oscillator power amplifier (MOPA) configured DIAL instrument and is used as the seeding source for the water vapor DIAL transmitter. The continuouswave $(\mathrm{cw})$ output from this ECDL is used to injection seed a tapered semiconductor optical amplifier (TSOA). The cw output of this first TSOA is injection seeded into a second TSOA that is operated in a saturation regime using a pulsed drive current producing up to $1.8 \mu \mathrm{J}$ pulses with a 1- $\mu$ s pulse duration and a pulse repetition frequency of $20 \mathrm{kHz}$. The pulsed output of the second TSOA is beam expanded to decrease the divergence of the DIAL transmitter to approximately $100 \mu \mathrm{rad}$, and the output is then sent into the atmosphere. Light scattered by the atmosphere is collected using a commercial SchmidtCassegrain telescope with a 28 -cm-diameter primary 
mirror. Light collected by the telescope passes through a focus and is then incident on a lens used to collimate the light. The collimated light passes through a narrowband filter with a center wavelength of $828.06 \mathrm{~nm}$ (air) and a full-width at half-maximum (FWHM) linewidth of $0.25 \mathrm{~nm}$. After the narrowband filter, the light is focused and launched into a multimode fiber with a core diameter of $105 \mu \mathrm{m}$ and a numerical aperture of NA $=0.22$ that acts as the system field stop, yielding a far-field full angle field of view of $170 \mu \mathrm{rad}$. A fiber-coupled photoncounting avalanche photodiode (APD) module is used to detect the collected optical signal. The laser transmitter comes into overlap with the DIAL receiver at $500 \mathrm{~m}$.

The evaluation of the temperature sensitivities of water vapor absorption lines in the 820-840-nm spectral region were studied using the methods presented by Browell et al. (1991), leading to the selection of this water vapor absorption line for number density profiles at $828.187 \mathrm{~nm}$ (vacuum) (the online wavelength). A summary of the water vapor DIAL transmitter and the receiver specifications are shown in Table 2, where the laser transmitter requirements for accurate water vapor profiling are also shown for comparison.

The water vapor DIAL operates autonomously using custom control software developed in the Labview programming environment. The control program tunes the DIAL laser transmitter to the online wavelength. The backscattered returns collected by the water vapor DIAL receiver are sampled by a $20-\mathrm{MHz}$ multichannel-scalar (MCS) card for a user-defined time of typically $1 \mathrm{~min}$. The control program then tunes the DIAL laser transmitter to the offline wavelength and this process is repeated. Data presented in this paper used 6 min of averaged online data and $6 \mathrm{~min}$ of averaged offline data to create one range-resolved number density profile using the DIAL equation (Kovalev and Eichinger 2004). Water vapor number density time series are then derived by creating a 12-min running-average window across the full dataset. A nearest-neighbor interpolation algorithm is then used to smooth the data in space and time to increase the viewing resolution of the water vapor time series.

\section{d. Ground-based nephelometer}

The scattering component of the aerosol extinction was measured with an M-903 Integrating Nephelometer (Radiance Research, Seattle, Washington) with an equivalent wavelength of $550 \mathrm{~nm}$. The nephelometer was operated in a room with the temperature slightly above ambient. This, along with the fact that the humidity was always considerably below saturation, resulted in a dry aerosol. The inlet tube was approximately $1 \mathrm{~m}$ in length and calculations indicate insignificant loss of aerosol through the sampling line. This was verified by comparing the scattering
TABLE 2. Laser transmitter and receiver specifications for the diode-laser-based water vapor DIAL. Laser transmitter requirements for water vapor DIAL retrievals with an error due to individual laser properties of $<3 \%$ are listed in the right-hand column.

\begin{tabular}{lcc}
\hline \hline \multicolumn{1}{c}{ Parameters } & Measured values & Requirement \\
\hline$\lambda_{\text {on }}, \lambda_{\text {side-line }}, \lambda_{\text {off }}$ & $828.187-828.1936-$ & \\
$(\mathrm{nm}$, vacuum $)$ & 828.287 & \\
PRF $(\mathrm{kHz})$ & 20.0 & \\
Pulse width $(\mu \mathrm{s})$ & 1 & $<296$ \\
Pulse energy $(\mu \mathrm{J})$ & $\sim 2.0$ & \\
Transmitter line width & $<0.300$ & \pm 160 \\
$\quad($ FWHM, MHz) & & \\
Frequency stability & \pm 88 & \\
$\quad($ MHz $)$ & & \\
Spectral purity & 0.995 & \\
Telescope diameter & 28 & \\
$\quad(\mathrm{~cm})$ & & \\
Far-field full FOV & $\sim 170$ & \\
$\quad(\mu$ rads $)$ & & \\
Filter bandwidth & & \\
$\quad($ FWHM; pm) & & \\
\hline
\end{tabular}

coefficient with and without the sampling line. Airflow through the instrument was set at 5 liters $(\mathrm{min})^{-1}$. Data were averaged and logged over $15 \mathrm{~min}$ and calibration was executed by filling the scattering volume with CF-22 before and after the experiment. The instrumental 0 point was checked every few days by inserting an absolute filter. According to the drifts in the 0 point and in the calibration, we infer that the measured scattering component of the aerosol extinction is accurate to $\pm 1 \times 10^{-6} \mathrm{~m}^{-1}$.

\section{e. Summary of data products}

The data products for the water vapor DIAL instrument include the range-corrected return signal as a function of range for both the online and offline wavelengths. These return signals at the online and offline wavelengths can be used along with the DIAL equation to calculate water vapor number density profiles. The water vapor number density profiles can be used along with modeled temperature and pressure profiles to calculate relative humidity profiles. The eye-safe offline wavelength of the DIAL can also be used to display aerosol structural features.

The data products for the two-color lidar instrument include the return signal at both the 532- and 1064-nm wavelengths as a function of range. The inversion of the two-color lidar data using the Fernald retrieval (Fernald et al. 1972; Fernald 1984) provides vertical profiles of the aerosol backscatter and extinction at both wavelengths as a function of the lidar ratio. An assumption of a constant lidar ratio is made to complete the lidar inversion. Integrating the aerosol extinction profile generated from the lidar inversion provides the aerosol optical depth for each wavelength. 


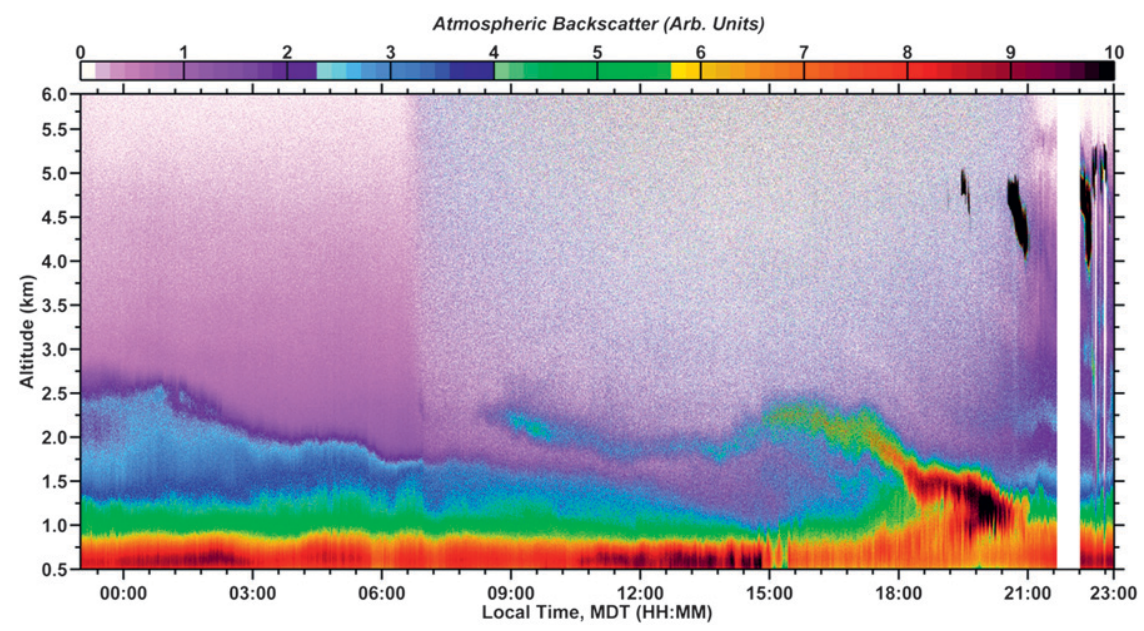

FIG. 1. A false-color plot of the range-corrected returns using the offline wavelength $(828.287 \mathrm{~nm})$ of the water vapor DIAL as a function of range and time. The water vapor DIAL is an eye-safe instrument and is capable of collecting continuous data.

The data products from the Cimel solar radiometer include the aerosol optical depth and the Angstrom exponents. The inversions applied to the almucantar scans completed by NASA through the AERONET program (Holben et al. 2001) provide the column-integrated aerosol phase function, the single-scatter albedo, the complex index of refraction, and the aerosol size distribution for accumulation and coarse modes. The data product for the ground-based nephelometer provides measurements of the scattering component of the aerosol extinction at $550 \mathrm{~nm}$.

\section{Observational data and analysis}

The eye-safe water vapor DIAL was operated over a 24-h period beginning at 2300 mountain daylight time (MDT) on 27 August 2009. A false-color plot of the rangecorrected returns using the offline data at $828.287 \mathrm{~nm}$ collected with the water vapor DIAL as a function of range and time is shown in Fig. 1. The wind was out of the east until 0400 MDT on 28 August 2009 with the wind speed dropping from 5 to less than $1 \mathrm{~m} \mathrm{~s}^{-1}$. The wind remained out of the east with a wind speed of less than $1 \mathrm{~m} \mathrm{~s}^{-1}$ until 0900 MDT. At approximately 0900 MDT, the wind direction shifted to out of the north with a wind speed of approximately $1 \mathrm{~m} \mathrm{~s}^{-1}$. This shift in the wind direction corresponds to the appearance of the elevated aerosol layer at approximately $2 \mathrm{~km}$. The wind direction again shifted at approximately 1500 MDT to out of the east with an increase in wind speed to $5 \mathrm{~m} \mathrm{~s}^{-1}$. This shift in the wind direction and speed coincides with the increased aerosol loading seen in Fig. 1 at $2.5 \mathrm{~km}$ at approximately 1500 MDT. The wind velocity then increased from 5 to $7.5 \mathrm{~m} \mathrm{~s}^{-1}$ between 2000 and 0000 MDT on 29 August 2009. Clouds began appearing at approximately $4.5 \mathrm{~km}$ starting at $1800 \mathrm{MDT}$ on 28 August 2009. The wind speed and wind direction measurements were made using a ground-based weather station and correlate well with the direction of the zonal winds derived by the National Oceanic and Atmospheric Administration's (NOAA) Hybrid Single-Particle Lagrangian Integrated Trajectory (HYSPLIT) model, which is presented in section 4 a.

A plot of the aerosol optical depth measured with the scanning solar radiometer is shown in Fig. 2. The triangles (squares, circles) represent the measured aerosol optical depth as a function of time at the 532-nm $(675,1020 \mathrm{~nm})$ wavelengths. The aerosol optical depth at $532 \mathrm{~nm}$ was calculated using a linear interpolation of data collected at the 500- and 675-nm channels. The aerosol optical depth at the 532-nm wavelength was also calculated using the wavelength-dependent Angstrom exponent (Eck et al. 1999). The aerosol optical depth at the 532-nm wavelength was calculated using the average Angstrom exponent calculated using the 440- and 500-nm wavelength pair and the 500- and 675-nm wavelength pair. The aerosol optical depths estimated from the interpolation of the AERONET data using both the linear interpolation and the Angstrom exponent were within $3.5 \%$. The solid black line in Fig. 2 represents the ratio of the 532-1020-nm aerosol optical depth and is related to the ratio of the aerosol extinction at $532-1020 \mathrm{~nm}$. This changing spectral ratio of the aerosol optical depth indicates that the aerosol composition is changing as the day progresses. The aerosol composition will be examined further in the next section when the aerosol optical properties are discussed in terms of previously developed aerosol models (Omar et al. 2009; 


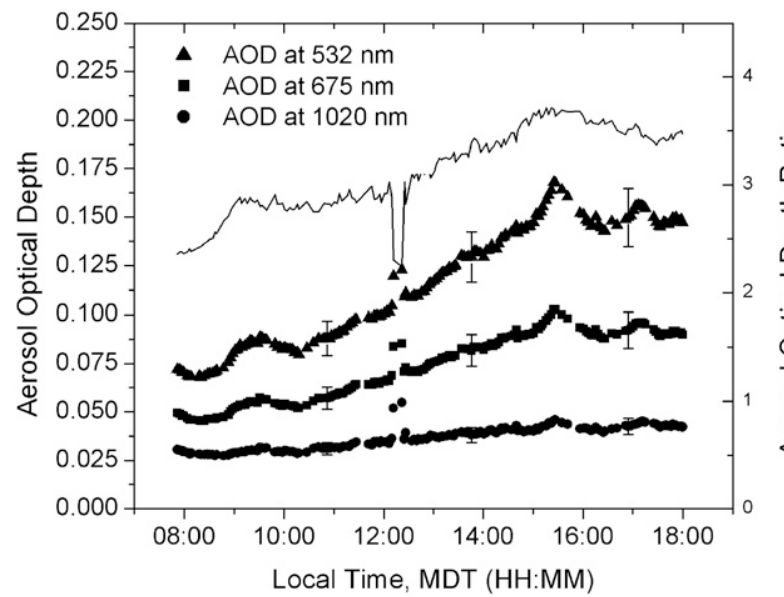

FIG. 2. Plot of the aerosol optical depth as a function of time for 28 Aug 2009. The triangles (squares, circles) represent the AOD at the 532-nm $(675 \mathrm{~nm}, 1020 \mathrm{~nm})$ wavelength. The solid black line represents the ratio of the AOD at $532 \mathrm{~nm}$ to the AOD at $1020 \mathrm{~nm}$.

Omar et al. 2005; Reagan et al. 2004; Cattrall et al. 2005; Wang et al. 2005).

The two-color lidar data collection time was limited from 1430 to 2300 MDT on 28 August 2009, the period when Federal Aviation Administration (FAA) permission was obtained to operate this non-eye-safe lidar instrument. The inversion of the two-color lidar data was completed using the aerosol optical depth shown in Fig. 2 as an independent constraint on the lidar inversion. For the 532-nm channel of the two-color lidar, a lidar ratio, $S_{a}$, is chosen; the inversion is completed using the Fernald inversion technique; and an aerosol optical depth is calculated using the aerosol extinction resulting from the lidar inversion. A constant lidar ratio assumption is used along with the aerosol optical depth constraint to complete the lidar inversion. Because of this assumption needed to complete the lidar inversion, the variability of the lidar ratio as a function of height is lost. Because the twocolor lidar does not come into full overlap until a range of $750 \mathrm{~m}$, the aerosol extinction from the ground to the $750-\mathrm{m}$ range is assumed constant and equal to the value at $750 \mathrm{~m}$. The validity of this assumption will be discussed further when the scattering component of the aerosol extinction measured using the nephelometer is presented. The aerosol optical depth resulting from the lidar inversion is then compared to the aerosol optical depth measured by the solar radiometer. This process is repeated for the 1064-nm channel of the two-color lidar. A plot of the aerosol optical depth averaged from 1500 to 1800 MDT on 28 August 2009 is shown as a function of the lidar ratio $S_{a, 532 \mathrm{~nm}}\left(S_{a, 1064 \mathrm{~nm}}\right)$, in Fig. 3 (Fig. 4$)$ measured using the $532-\mathrm{nm}(1064 \mathrm{~nm})$ channel of the two-color lidar. The solid squares represent the average calculated aerosol

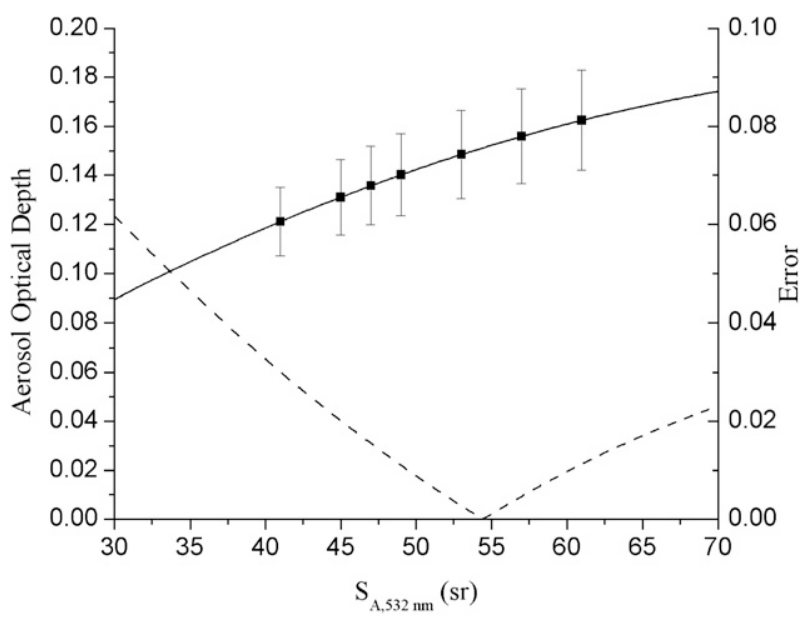

FIG. 3. Plot of the average AOD at $532 \mathrm{~nm}$ as a function of $S_{a, 532 \mathrm{~nm}}$. The solid squares represent the AOD calculated from the lidar inversion averaged between 1500 and 1800 MDT. The solid line represents a polynomial fit to these calculated values for the AOD. The dashed line represents the absolute value of the difference between the calculated AOD using the results from the lidar inversion and the average value of the AOD measured using the solar radiometer.

optical depth as a function of $S_{a, 532 \mathrm{~nm}}\left(S_{a, 1064 \mathrm{~nm}}\right)$, while the error bars represent the standard deviation in the calculated aerosol optical depth. The solid line shown in Fig. 3 (Fig. 4) represents a polynomial fit to the aerosol optical depth as a function of $S_{a, 532 \mathrm{~nm}}\left(S_{a, 1064 \mathrm{~nm}}\right)$. The dashed line shown in Fig. 3 (Fig. 4) represents the absolute

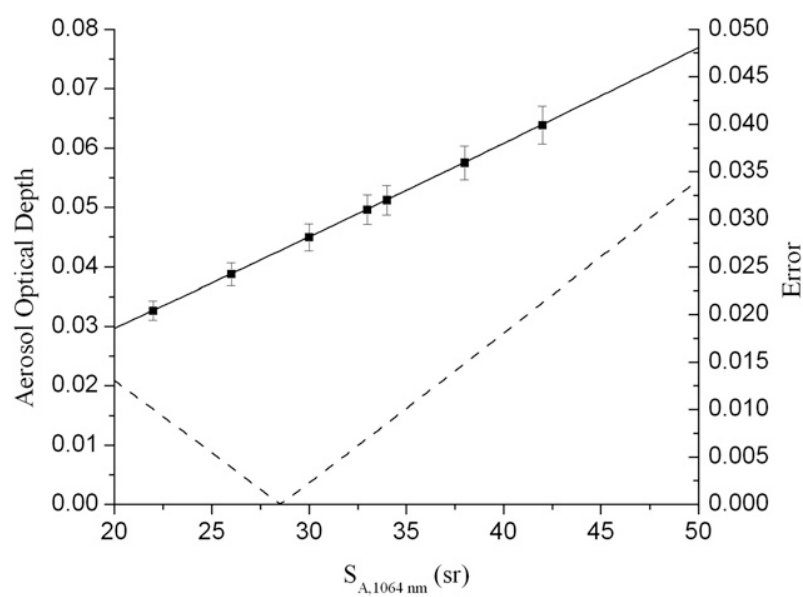

FIG. 4. Plot of the average AOD at $1064 \mathrm{~nm}$ as a function of $S_{a, 1064 \mathrm{~nm}}$. The solid squares represent the AOD calculated from the lidar inversion averaged between 1500 and 1800 MDT. The solid line represents a polynomial fit to these calculated values for the AOD. The dashed line represents the absolute value of the difference between the calculate AOD using the results from the lidar inversion and the average value of the AOD measured using the solar radiometer. 


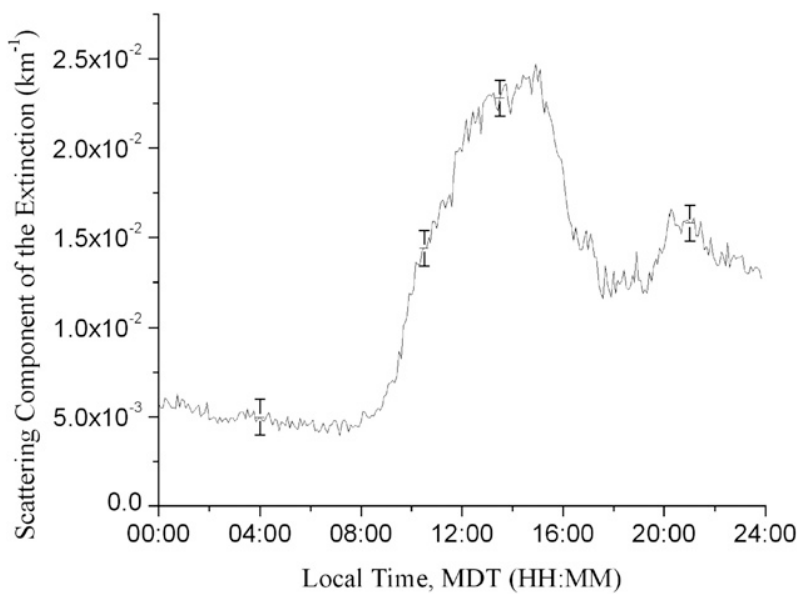

FIG. 5. The scattering component of the aerosol extinction at $550 \mathrm{~nm}$ as a function of time measured at the surface using the nephelometer.

value of the difference between the calculated aerosol optical depth and the average aerosol optical depth measured by the solar radiometer between 1500 and 1800 local time (LT) for the 532-nm (1064 nm) wavelength. A value of $S_{a, 532 \mathrm{~nm}}=54.5 \pm 9.0 \mathrm{sr}\left(S_{a, 1064 \mathrm{~nm}}=28.5 \pm 2.8 \mathrm{sr}\right)$ used in the Fernald lidar inversion yields an aerosol optical depth for the 532-nm (1064 nm) channel of the two-color lidar that matches with the aerosol optical depth measured by the solar radiometer. The error in the lidar ratio retrieved from the two-color lidar is calculated using the standard deviation of the aerosol optical depth (AOD) retrieved over the 15-min integration period.

The nephelometer measures the scattering component of the aerosol extinction of the aerosols at the 550-nm wavelength. A plot of the scattering component of the aerosol extinction as a function of time is shown in Fig. 5. The nephelometer measurement can be compared with the scattering component of the aerosol extinction retrieved using the two-color lidar at the 532-nm wavelength. While the two-color lidar retrieves the total aerosol extinction, the scattering extinction can be estimated by multiplying the total aerosol extinction by the singlescatter albedo retrieved using the solar radiometer, which has an average value of $0.921 \pm 0.012$ based on the solar radiometer measurements between 1500 and $1800 \mathrm{LT}$. Plots of the scattering component of the aerosol extinction as a function of time for the two-color lidar and the ground-based nephelometer are shown in Fig. 6. The dashed line represents the scattering component of the aerosol extinction measured at the surface using the nephelometer, while the solid line represents the scattering component of the aerosol extinction estimated using the solar-radiometer-derived single-scatter albedo and the aerosol extinction retrieved at an altitude of $750 \mathrm{~m}$

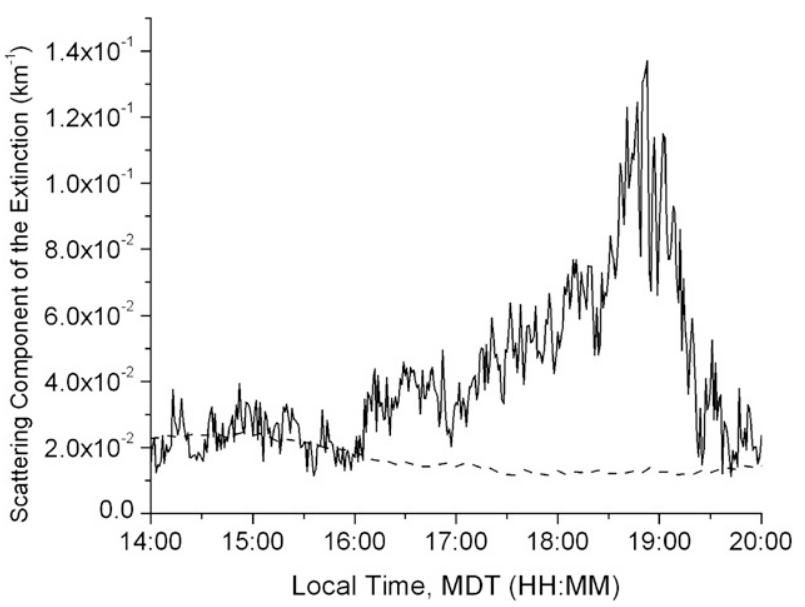

FIG. 6. The scattering component of the aerosol extinction as a function of time. The dashed line represents surface measurements using the nephelometer while the solid line represents measurements made using the single-scatter albedo and aerosol extinction measurements made at $750 \mathrm{~m}$.

using the 532-nm channel of the two-color lidar. Good agreement between the nephelometer and the lidar data is seen from 1400 to 1600 MDT. The scattering component of the aerosol extinction measured using the two-color lidar starts to diverge from the scattering component of the aerosol extinction measured by the nephelometer between 1600 and 1900 MDT. This is most likely due to the downward mixing of the thin layer of aerosols seen in Fig. 1 starting to affect the extinction measurements at $750 \mathrm{~m}$, but not yet affecting the ground-based measurements. The agreement between the scattering component of the aerosol extinction measurements measured using the ground-based nephelometer and the twocolor lidar at $750 \mathrm{~m}$ between 1400 and 1600 MDT lends credence to the assumption that the aerosol extinction below $750 \mathrm{~m}$ is constant. However, when the aerosol layer begins affecting the two-color lidar measurements at $750 \mathrm{~m}$, but not the ground-based measurements, this constancy assumption no longer holds and some error in the calculated aerosol optical depth from the two-color lidar results. This error contribution to the aerosol optical depth is estimated to be less than about $5 \%$ for the 1600 1900 MDT time period.

A false-color plot of the aerosol extinction as a function of time is shown in Fig. 7 for the 532-nm wavelength. The returns used to calculate the backscatter and extinction profiles were down-sampled from the original sampled resolution of $0.75 \mathrm{~m}$ to $15 \mathrm{~m}$ to provide an increase in the signal-to-noise ratio. Profiles of the aerosol extinction and relative humidity at $1500,1600,1700$, and 1800 MDT are shown in Fig. 8. In this figure, the aerosol extinction from $750 \mathrm{~m}$ to $5 \mathrm{~km}$ was retrieved using the two-color lidar, 


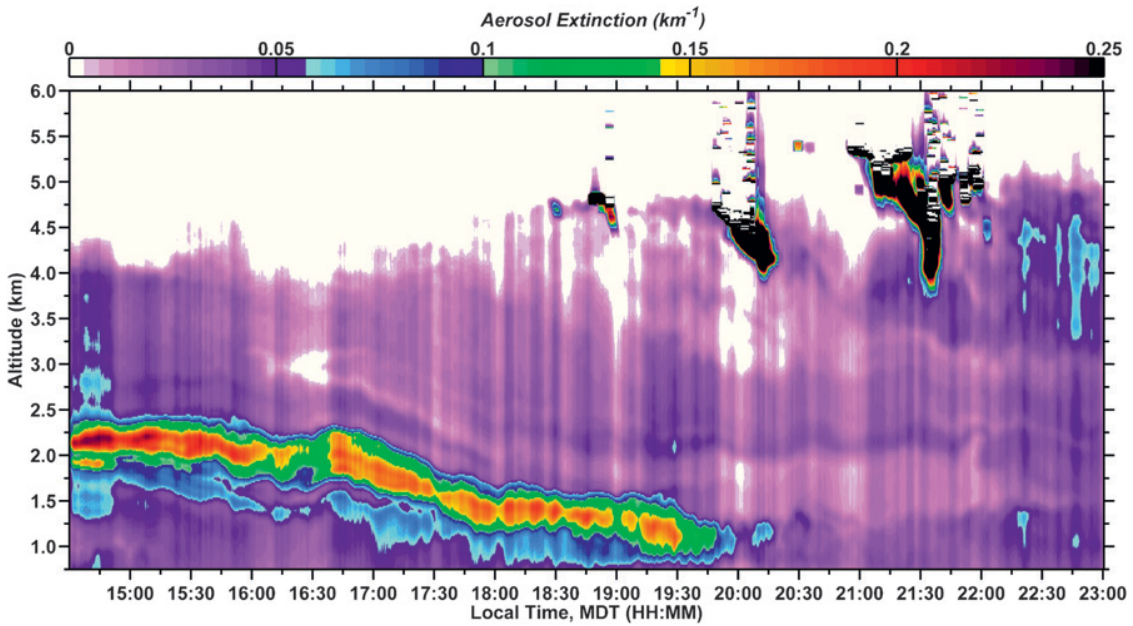

FIG. 7. False-color plot of the aerosol extinction as a function of time. The top of the boundary layer ranges from approximately 1.5 to $2.5 \mathrm{~km}$ with cumulus clouds appearing beginning at approximately 1900 MDT at the boundary layer.

while the aerosol extinction at the surface was determined using the scattering nephelometer measurement and the solar-radiometer-retrieved single-scatter albedo. The relative humidity was retrieved from the water vapor DIAL. The change in aerosol extinction between the ground and $750 \mathrm{~m}$ was assumed to be linear.
The water vapor DIAL provides range-resolved water vapor profiles as a function of time. A false-color plot of the water vapor number density as a function of range and time is shown in Fig. 9. Temperature profiles can be estimated using the surface temperature and a lapse rate of $-10^{\circ} \mathrm{C} \mathrm{km}^{-1}$, while pressure profiles can be estimated
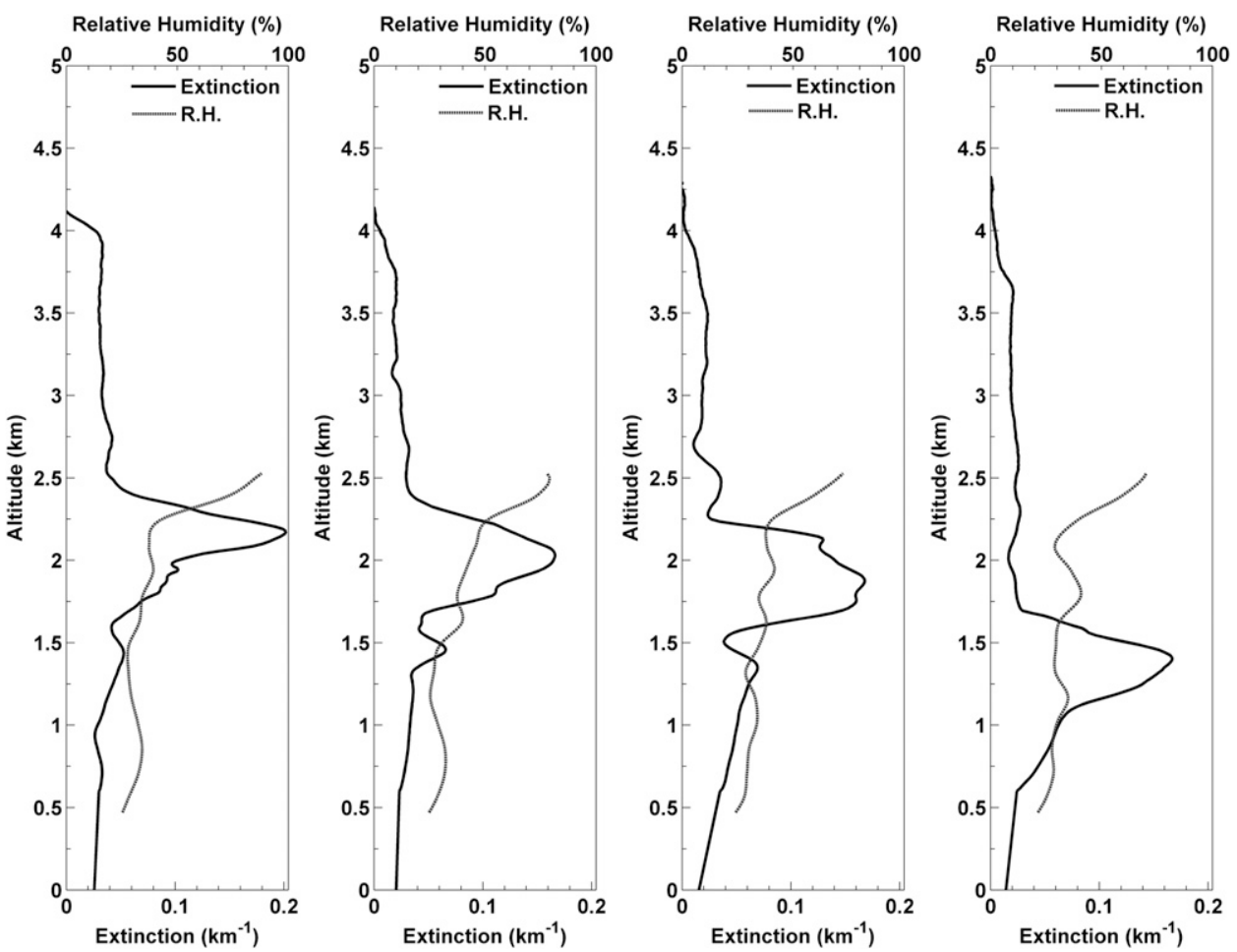

FIG. 8. A plot of the aerosol extinction and relative humidity as a function of range at (left to righ) 1500 , 1600,1700 , and 1800 MDT. The aerosol extinction at the surface was measured using the scattering nephelometer. The two-color lidar comes into overlap at $750 \mathrm{~m}$. 


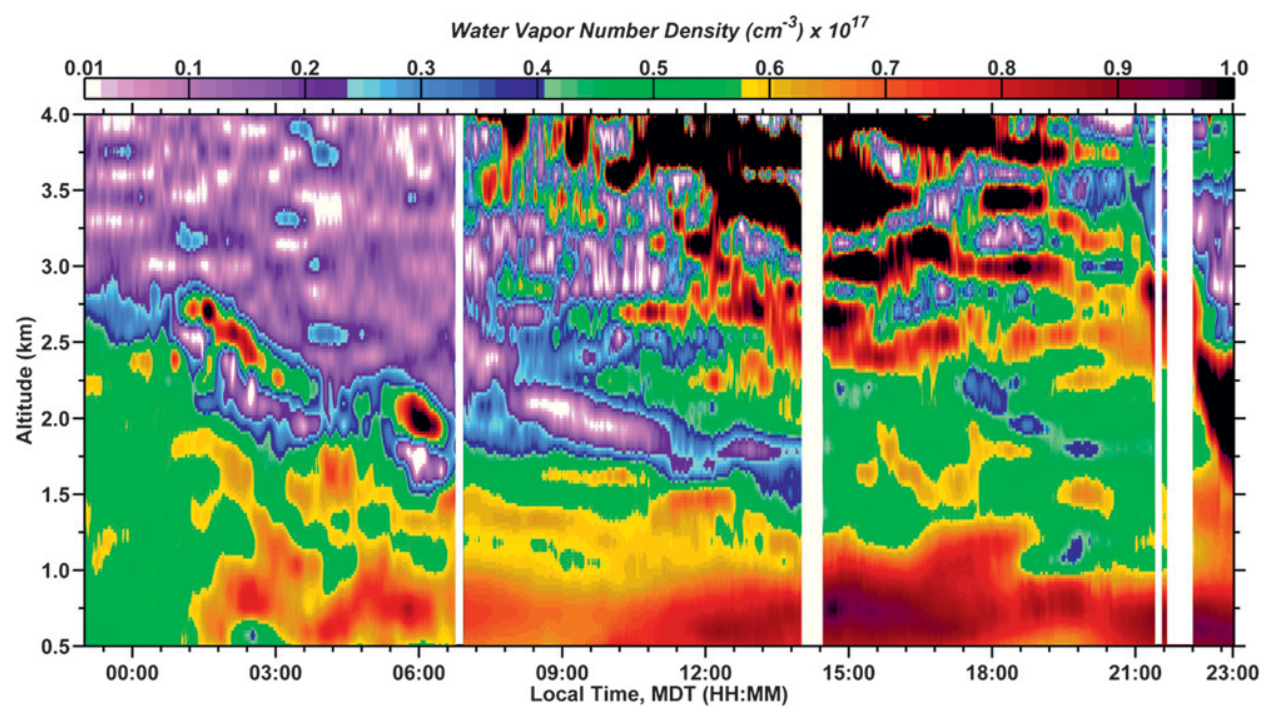

FIG. 9. (left to right) Water vapor number density as a function of altitude and time beginning at 2300 MDT 27 Aug 2009 and continuing through 2300 MDT 28 Aug 2009. The water vapor number density ranges from 0.1 (white) to $10 \times 10^{16} \mathrm{~cm}^{-3}$ (black).

using the surface pressure along with a modeled pressure profile (Machol et al. 2004), allowing the relative humidity to be calculated from the water vapor number density data shown in Fig. 9. The relative humidity as a function of range and time is shown in Fig. 10.

The hygroscopic growth of aerosols can have a significant impact on the aerosol particle size and strongly influences the radiative forcing resulting from the aerosol direct effect (Wulfmeyer and Feingold 2000; Kotchenruther et al. 1999). The hygroscopic growth of aerosols requires a high relative humidity over approximately $80 \%$ before the aerosol backscatter is appreciably affected (Wulfmeyer and Feingold 2000; Kotchenruther et al. 1999). As can be seen in Figs. 8 and 10, during this observation period, the relative humidity in the vicinity of the aerosol layer below approximately $2.5 \mathrm{~km}$ remains relatively low, below $60 \%$, indicating that very little hygroscopic growth of the aerosol is taking place.

The lidar ratio at 532 and $1064 \mathrm{~nm}$ can be retrieved from the data provided by the solar radiometer. Using the

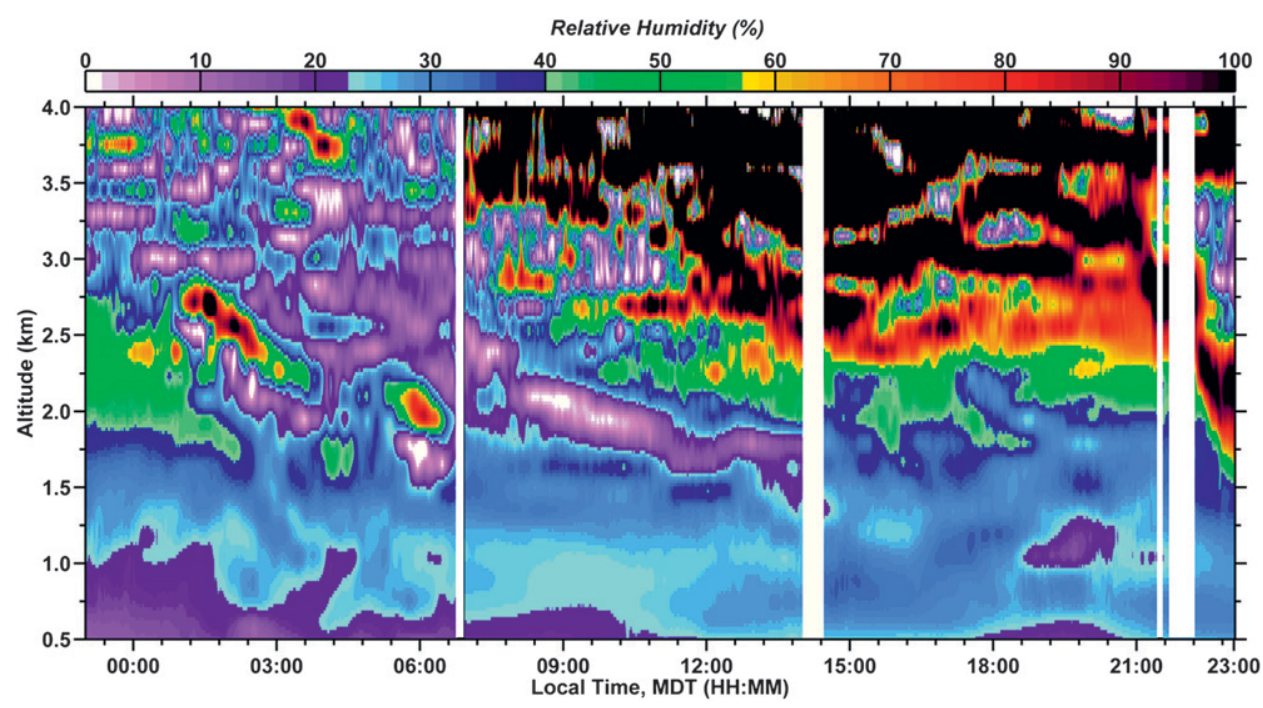

FIG. 10. The relative humidity as a function of range and time estimated using the data shown in Fig. 9. The temperature and pressure profiles are estimated using the surface temperature and pressure and a model atmosphere. 


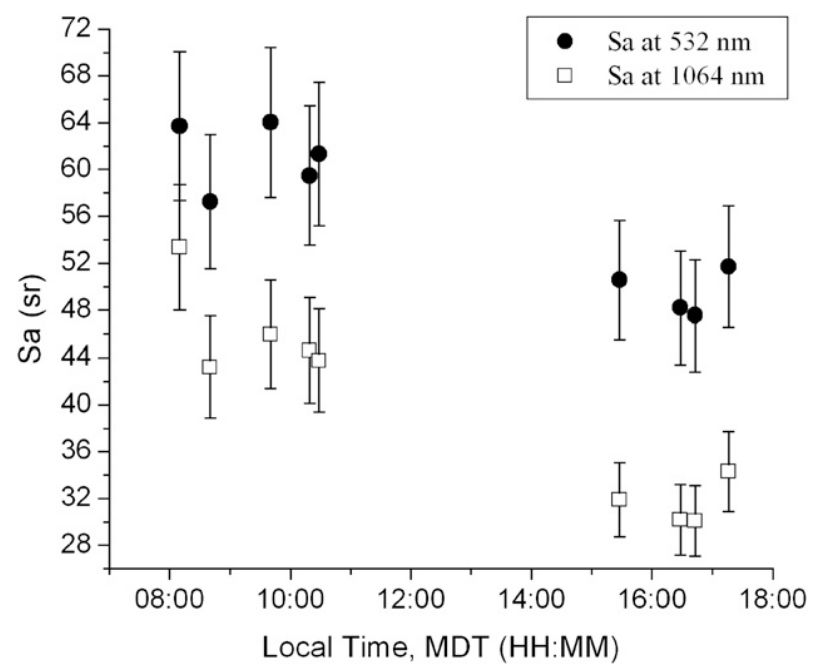

FIG. 11. Plot of the lidar ratio $S_{a}$ as a function of time. The lidar ratio at $532 \mathrm{~nm}(1064 \mathrm{~nm})$ is plotted as the circles (squares). The change in the $S_{a}$ ratio at both wavelengths between measurements made in the morning and afternoon indicate a change in the aerosol species.

single-scatter albedo and phase function from the inversion of the solar radiometer data, the lidar ratio can be calculated as $S_{a, \lambda}=4 \pi / \omega_{o, \lambda} P_{\lambda}(180)$, where $\omega_{o, \lambda}$ is the single-scatter albedo at the wavelength $\lambda$ and $\mathrm{P}_{\lambda}(180)$ is the value of the phase function at $180^{\circ}$ at the wavelength $\lambda$. The single-scatter albedo and phase function at $532 \mathrm{~nm}$ are calculated using a linear interpolation of the 500- and 675-nm data. A plot of the lidar ratio at both the 532- and 1064-nm wavelengths is shown in Fig. 11 as a function of time. Data were not taken between 1100 and 1400 MDT on 28 August 2009 due to broken cloud cover affecting the almucantar scanning of the solar radiometer. The circles (squares) represent the lidar ratio at the 532-nm $(1064 \mathrm{~nm})$ wavelength. From Fig. 11, it can be seen that the lidar ratios change for data collected during the morning and data collected during the afternoon. The lidar ratio retrieved from the radiometer data collected in the morning (afternoon) for the 532-nm wavelength is $S_{a, 532 \mathrm{~nm}}=61.2 \pm 6.7 \mathrm{sr}\left(S_{a, 532 \mathrm{~nm}}=49.5 \pm 5.3 \mathrm{sr}\right)$. The lidar ratio retrieved from the radiometer observations in the morning (afternoon) for the 1064-nm wavelength is $S_{a, 1064 \mathrm{~nm}}=44.4 \pm 4.6 \mathrm{sr}\left(S_{a, 1064 \mathrm{~nm}}=31.6 \pm 3.7 \mathrm{sr}\right)$. The lidar ratios for both the $532-\mathrm{nm}(1064 \mathrm{~nm})$ wavelength retrieved in the afternoon using the two-color lidar are $54.5 \pm 9.0 \mathrm{sr}\left(S_{a, 1064 \mathrm{~nm}}=28.5 \pm 2.8 \mathrm{sr}\right)$, agreeing with the lidar ratios obtained from the solar radiometer observations. Because of not having FAA permission to operate the non-eye-safe lidar, two-color lidar data were not available during the morning hours.

The aerosol volume distribution obtained by inverting the solar radiometer measurements is shown in Fig. 12.

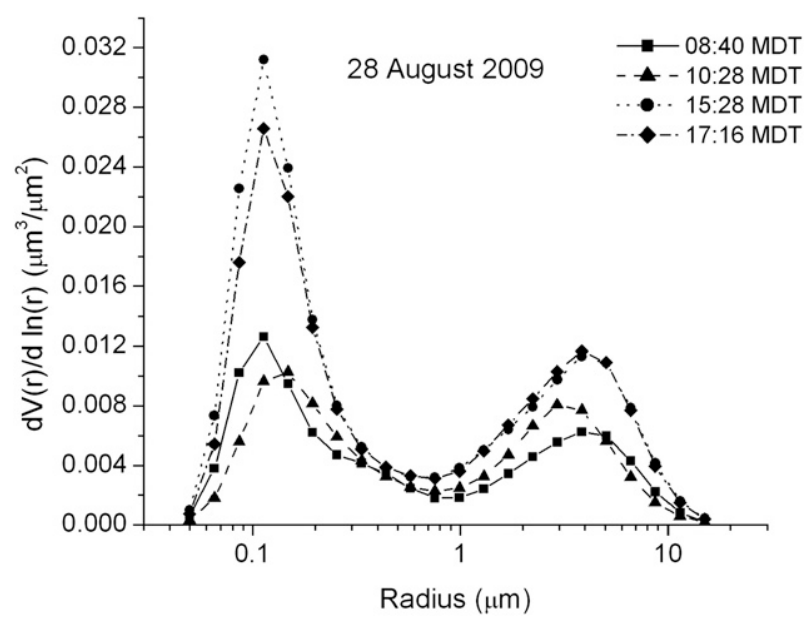

FIG. 12. A plot of the bimodal lognormal size distributions retrieved from the solar radiometer observations on 28 Aug 2009. The solid line (dashed line, dotted line, dash dotted line) represents measurements made using the almacantar scan of the solar radiometer at 0840 MDT $(1028,1528,1716$ MDT). The fine mode is much larger for measurements made in the afternoon as compared to measurements made in the morning, indicating that a new aerosol species is present.

The squares connected by a solid line (triangles connected by a dashed line, circles connected by a dotted line, and diamonds connected by a dashed-dotted line) represent retrievals of the volume distribution made at $0840 \operatorname{MDT}(1028,1528$, and 1716 MDT). A change in the aerosol fine- and coarse-mode fractions by volume between the morning and afternoon indicates a change in the aerosol composition, which will be further discussed in the next section.

\section{Discussion}

\section{a. Comparison of aerosol optical properties with aerosol models}

Aerosol models useful for assessing and constraining lidar retrievals have been developed by Cattrall et al. (Reagan et al. 2004; Cattrall et al. 2005; Wang et al. 2005) and Omar et al. (Omar et al. 2005, 2009) from extensive analyses of AERONET (Holben et al. 2001) retrieval data. Omar et al.'s models were derived using cluster analysis techniques on the complete AERONET database, while Cattrall et al.'s models were derived by regional and time of year segregation of the AERONET database to isolate different types of aerosols. Both datasets included many thousands of AERONET retrievals, which enabled meaningful statistical assessments and groupings. Both sets of models include the core groupings of aerosol types that one would expect from an analysis of a global dataset such as aerosol types characterizing 
TABLE 3. A summary of the aerosol model parameters for the 532- and 1064-nm wavelengths derived by Omar et al. A complete list of aerosol model parameters can be found in Omar et al. $(2005,2009)$.

\begin{tabular}{|c|c|c|c|c|c|c|}
\hline Optical physical property & Dust & Smoke & Clean continental & Polluted continental & Clean marine & Polluted dust \\
\hline Lidar ratio $532 \mathrm{~nm}, S_{a, 532 \mathrm{~nm}}(\mathrm{sr})$ & 40 & 70 & 35 & 70 & 20 & 65 \\
\hline Lidar ratio $1064 \mathrm{~nm}, S_{a, 1064 \mathrm{~nm}}(\mathrm{sr})$ & 55 & 40 & 30 & 30 & 45 & 30 \\
\hline Fine fraction by volume & 0.223 & 0.329 & 0.050 & 0.531 & 0.025 & 0.241 \\
\hline Coarse fraction by volume & 0.777 & 0.671 & 0.950 & 0.469 & 0.975 & 0.759 \\
\hline Real index at $532 \mathrm{~nm}$ & 1.414 & 1.517 & 1.451 & 1.404 & 1.400 & 1.452 \\
\hline Imaginary index at $532 \mathrm{~nm}$ & 0.0036 & 0.0234 & 0.0032 & 0.0063 & 0.0006 & 0.0109 \\
\hline Real index at $1064 \mathrm{~nm}$ & 1.495 & 1.541 & 1.451 & 1.439 & 1.393 & 1.512 \\
\hline Imaginary index at $1064 \mathrm{~nm}$ & 0.0043 & 0.0298 & 0.0032 & 0.0073 & 0.0006 & 0.0137 \\
\hline
\end{tabular}

urban-industrial or pollution, dust, smoke/biomass burning, and marine-oceanic sources. These models yield similar but not identical lidar parameters as well as some model variations such as the polluted continental and polluted marine aerosol models in the Omar et al. set and SE Asia in the Cattrall et al. set, which mainly reflect slight differences in the regional-time of year segmentations of the AERONET database. The Cattrall et al. models are given in lidar-related spectral parameterizations including the aerosol lidar ratio at $550 \mathrm{~nm}$ and the $550-/ 1020-\mathrm{nm}$ spectral ratios of the aerosol lidar ratio, backscatter, extinction, and Angstrom exponent, and nonspherical particle effects are included in the dust (spheroids) model. The wavelengths of 550 and $1020 \mathrm{~nm}$ used in developing the Cattrall et al. models are close enough to the frequently employed lidar wavelengths of 532 and $1064 \mathrm{~nm}$ to not require wavelength corrections when applying the models to lidar data at these wavelengths since the slight wavelength differences are within the inherent uncertainty in the models (Reagan et al. 2004; Cattrall et al. 2005; Wang et al. 2005). The statistical spreads (standard deviations) of the various parameters in the Cattrall et al. models were also determined as a part of the analysis and provide important confidence bounds or windows on fitting the models to the data. For example, the standard deviations of the lidar ratio at $550 \mathrm{~nm}$ for the various aerosol models are within approximately $15 \%$, permitting reasonably bounded lidar retrievals. The Omar et al. models give the aerosol physical parameters including particle size distribution and complex refractive index necessary to calculate the optical scattering properties of the particles and obtain parameterizations similar to those of the Cattrall et al. models. In a more recent paper, Omar et al. (2009) have updated and revised their models to reflect more recent observational confirmations and to define more appropriate model groupings for application to Cloud-Aerosol Lidar and Infrared Pathfinder Satellite Observations (CALIPSO) lidar observations. The aerosol parameters for these revisedupdated Omar et al. (2009) models are given in Table 3. Similarly, Table 4 gives the aerosol parameters for the Cattrall et al. (2005) models, excluding the dust (spheres) model, which is not considered practical, and in addition including a rural continental model. The rural continental model was defined by the same procedures and at the same time as the other Cattrall et al. models, but it was not included in the Cattrall et al. (2005) publication. It was defined from AERONET data for several midwestern AERONET sites with a constraint of only including data with 550-nm aerosol optical depths less than or equal to 0.15 to define what was first thought of as a clean continental model. After some consideration, it was concluded that the 0.15 aerosol optical depth cutoff likely included enough pollution influence to not yield a truly clean continental aerosol model, which is why it was not included in the 2005 publication. However, it still gives some measure of the continental aerosol characteristics and is included here for comparison with the updated Omar et al. models. It can be seen that the $S_{a}$ 's given in Tables 3 and 4 are in reasonable agreement for

TABLE 4. A summary of the aerosol model parameters for the 550- and 1020 -nm wavelengths derived by Cattrall et al. Here, $\beta_{550 \mathrm{~nm}}$ $\left(\beta_{1020 \mathrm{~nm}}\right)$ is the aerosol backscatter at the $550-\mathrm{nm}(1020 \mathrm{~nm})$ wavelength, and $\sigma_{550 \mathrm{~nm}}\left(\sigma_{1020 \mathrm{~nm}}\right)$ is the aerosol extinction at $550 \mathrm{~nm}$ $(1020 \mathrm{~nm})$. A complete description of the aerosol model parameters can be found in Cattrall et al. (2004), Cattrall et al. (2005), Reagan et al. (2004), and Wang et al. (2005).

\begin{tabular}{lcccccc}
\hline \hline \multicolumn{1}{c}{ Optical-physical property } & Biomass burning & SE Asia & Urban-industrial & Oceanic & Dust & Rural continental \\
\hline Lidar ratio $550 \mathrm{~nm}, S_{a, 550 \mathrm{~nm}}(\mathrm{sr})$ & $60 \pm 8$ & $58 \pm 11$ & $71 \pm 10$ & $28 \pm 5$ & $42 \pm 4$ & $49 \pm 8$ \\
Lidar ratio $1020 \mathrm{~nm}, S_{a, 1020 \mathrm{~nm}}(\mathrm{sr})$ & $29 \pm 4$ & $39 \pm 7$ & $37 \pm 5$ & $28 \pm 5$ & $35 \pm 3$ & $31 \pm 5$ \\
$\beta_{550 \mathrm{~nm}} / \beta_{1020 \mathrm{~nm}}$ & $1.8 \pm 0.3$ & $1.6 \pm 0.2$ & $1.6 \pm 0.2$ & $1.4 \pm 0.1$ & $1.1 \pm 0.1$ & $1.7 \pm 0.3$ \\
$\sigma_{550 \mathrm{~nm}} / \sigma_{1020 \mathrm{~nm}}$ & $3.8 \pm 0.4$ & $2.4 \pm 0.3$ & $3.3 \pm 0.5$ & $1.5 \pm 0.4$ & $1.2 \pm 0.1$ & $3 \pm 0.5$ \\
\hline
\end{tabular}


those models representing polluted-smoke-dominated aerosols, particularly for the nominal 550-nm wavelength.

The spectral backscatter and extinction ratios of the Cattrall et al. models were developed for use in the CRAM dual-wavelength lidar retrieval technique (Reagan et al. 2004; Wang et al. 2005) that provides a constrained means for selecting $S_{a}$ values that best fit the lidar data in the absence of other ways of estimating the $S_{a}$ 's. The CRAM approach and the Cattrall et al. models have been successfully applied to limited amounts of both Geoscience Laser Altimeter System (GLAS) and CALIPSO data (McPherson et al. 2010; Reagan et al. 2007; Reagan et al. 2006). Analysis of CALIPSO Saharan dust observations (McPherson and Reagan 2010) via CRAM and alternate estimates of $S_{a}$ at 532 and $1064 \mathrm{~nm}$, by the elevated layer direct transmittance approach, confirmed the 532-nm dust model $S_{a}$ of 42 , but led to a revised estimate for the 1064-nm dust model $S_{a}$ of 52, which agrees with the revised estimate for the Omar et al. dust model. The determinations of $S_{a}$ at 532 and $1064 \mathrm{~nm}$ obtained from the various instruments in the case study reported here provide an opportunity to further assess the utility of these aerosol models for interpreting multiwavelength lidar and solar radiometer observations.

Considering first the 0800-1100 MDT period for 28 August 2009, which, while not having aerosol optical depth constrained lidar retrievals of $S_{a}$ due to not having FAA approval to operate the two-color lidar, does have AERONET inversion retrievals of $S_{a}$ from the skyscanning solar radiometer measurements. These lidar ratios are shown in Fig. 11 and yield mean values of $S_{a, 532}=$ $61.2 \pm 6.7 \mathrm{sr}$ and $S_{a, 1064}=44.4 \pm 4.6 \mathrm{sr}$. The spectral extinction ratio is also available from the solar radiometer aerosol measurements, a plot of which is included in Fig. 2, yielding a mean value of $2.70 \pm 0.18$ for the same period. There is also a slight bump in the aerosol optical depth and the spectra extinction ratio in Fig. 2 from a little before 0900 MDT through approximately 1000 MDT, presumably due to the first intrusion of the elevated layer showing up at that time in Fig. 1, at about $2 \mathrm{~km}$ in height, but the backscattering and aerosol optical depth contributions from this layer appear relatively weak until intensifying later at approximately 1500 MDT. Checking the models in Tables 3 and 4 , it can be see that these $S_{a}$ and spectral extinction ratio values match rather well with the Cattrall et al. SE Asia model parameters. This may at first glance seem surprising, but the shape of the SE Asia model volume size distribution is quite similar to the AERONET size distributions obtained from inversions of the skyscanning solar radiometer measurements between 0800 and 1100 MDT and are shown in Fig. 12. As discussed by Cattrall et al. (2005), the SE Asia model was defined to reflect the fact that the AERONET size distribution retrievals for this region generally featured a more significant coarse mode, though still smaller (in peak value) than the fine mode than that of either the biomass burning or urban-industrial models, presumably due to less controlled-lower temperature combustion emissions (e.g., from power generation and domestic coal-wood burning) in the region. The coarse modes for the A.M. distributions (as well as for the P.M. distributions) shown in Fig. 12 likely stem mainly from crustal-derived/dust aerosols, whereas the generally sulfate-dominated fine mode likely has some influence from local pollution sources in and around Bozeman (in addition to the pervasive influx of more widespread sources). It is interesting to note that over the period from about 1100 to 1500 LT (when unfortunately no solar radiometer sky scan retrievals were obtained) the backscatter in the layer just above the ground (red area in Fig. 1 up to $\sim 750 \mathrm{~m}$ ) seems to intensify; the spectral extinction ratio, shown in Fig. 2, steadily increases from 2.7 to 3.5; and the nephelometer scattering signal in Fig. 5, which is mostly due to fine-mode particle scattering, also steadily increases, more than doubling in strength. It would seem that these changes are most likely due to fine-mode growth arising from increased human-caused daytime activities in and around Bozeman coupled with atmospheric photochemical effects.

For the 1500-1800 MDT period, when both lidar and solar-radiometer-derived retrievals of lidar ratios were obtained, the retrieved lidar ratios were found to be in very good agreement with each other, but significantly decreased from the A.M. solar-radiometer-derived lidar ratio retrievals. The change is not surprising in view of the significant changes that occurred around 1500 MDT, as indicated in several of the previously cited figures, beginning with Fig. 1. As noted earlier, there was a significant change in wind speed and direction around 1500 MDT. Figure 1 indicates a decrease and the beginning of an upward spread of backscattering near the surface and also a notable increase in backscattering from the elevated layer about $2.5 \mathrm{~km}$ above ground. This is suggestive of a flushing out and dispersion of aerosols near the surface, due to changes in the wind, and the elevated layer intensification is also likely due to the change in wind bringing more of the transported elevated layer aerosols over the lidar observation site. This is consistent with the decrease in the scattering component of the aerosol extinction measured by the nephelometer and seen in Fig. 5 between about 1400 and 1600 MDT, as well as the increase in the lidar-retrieved aerosol extinction around $750 \mathrm{~m}$ starting at approximately 1600 MDT, as seen in Fig. 6. The lidar profile plots in Fig. 8 also show how strong the elevated layer extinction became during the 15001900 MDT period. Checking Tables 3 and 4, it can be seen that the Cattrall et al. rural continental model 


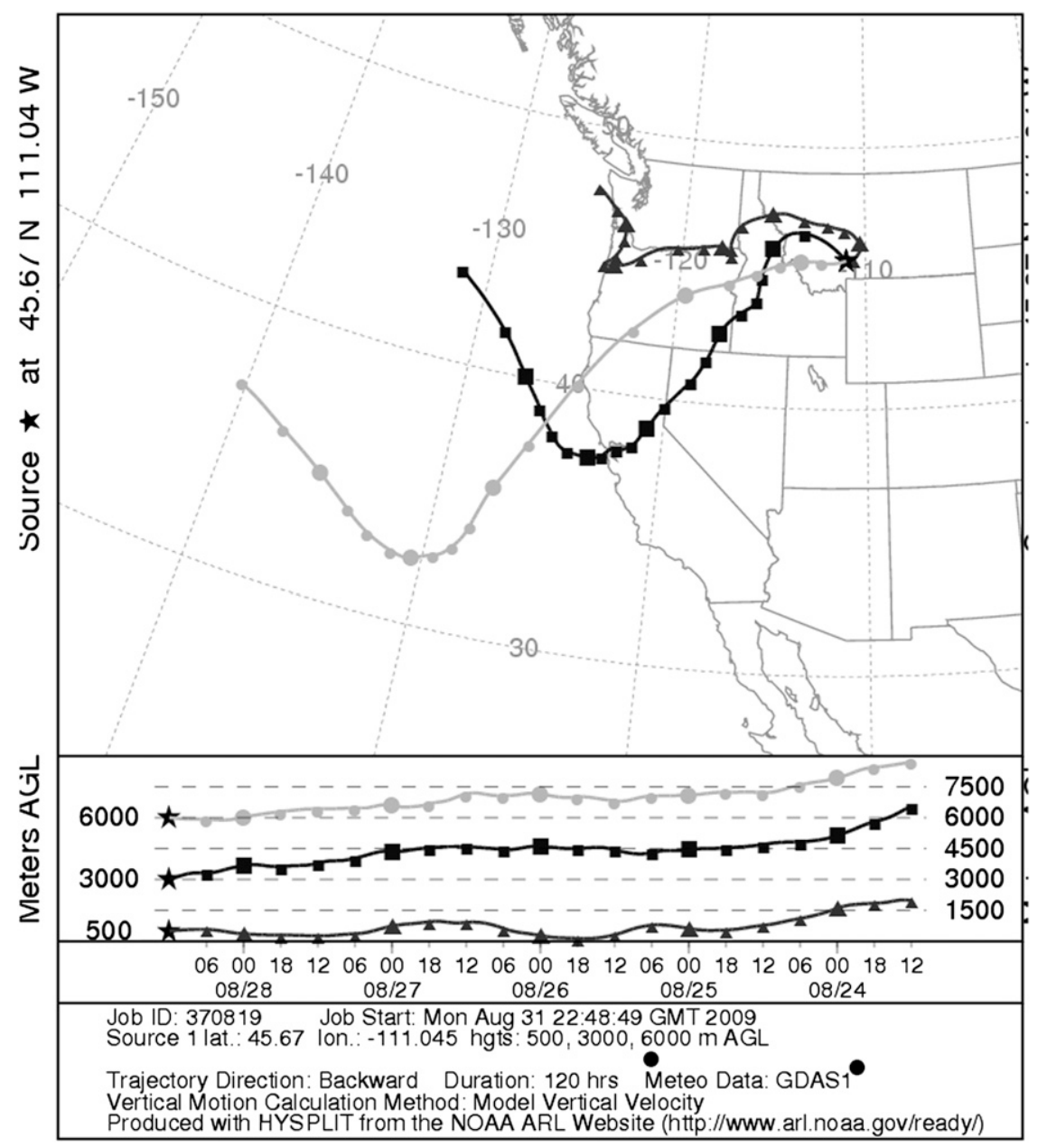

FIG. 13. The back-trajectory for the air mass over Bozeman for 28 Aug 2009. This back-trajectory analysis uses the HYSPLIT model developed by NOAA.

$S_{a}$ parameters come close to fitting the observations, albeit both the $S_{a, 532}$ (i.e., 49 sr versus the lidar retrieval of $54.5 \mathrm{sr}$ ) and the spectral extinction ratio (i.e., 3 versus the radiometer measurement of $3.55 \pm 0.10)$ are perhaps a little low. Also, considering the P.M. radiometer-derived size distribution retrievals shown in Fig. 12, it can be seen that the peak height of the fine mode has become significantly larger than the coarse-mode peak height (not a characteristic of the Cattrall et al. rural continental model), indicative of aerosols with a significant pollution/ smoke component. Smoke transported into the valley by the elevated layer is certainly a strong likelihood as seen from the back-trajectory paths shown in Fig. 13 based on the HYSPLIT model (information online at http://www. ready.arl.noaa.gov.HYSPLIT.php), as well as from the image shown in Fig. 14 from the Moderate Resolution Imaging Spectroradiometer (MODIS) aboard the Aqua satellite, and a knowledge that several fires had occurred in California, Washington, British Columbia, and northwestern Montana during this time period. Indeed, smoke and continental model aerosol mixtures of either the Omar et al. or Cattrall et al. models can provide good fits to the parameters retrieved from the lidar and radiometer observations.

The aerosol optical properties retrieved between 1430 and 2300 MDT and summarized in Table 5 can be compared to the aerosol models developed by Omar et al. (2005, 2009), which are summarized in Table 3. For the data collected between 1430 and 2300 MDT on 28 August 2009 , the lidar ratios of $S_{a, 532 \mathrm{~nm}}=54.5 \mathrm{sr}$ and $S_{a, 1064 \mathrm{~nm}}=$ $28.5 \mathrm{sr}$ were retrieved using the solar radiometer and lidar observations. These lidar ratios do not match any of the lidar ratios listed in Table 3, indicating that a mixture of aerosol species may have been present. A linear combination of the clean continental and smoke models described in Table 3 with $33 \%$ smoke and $67 \%$ clean continental yields lidar ratios of $S_{a, 532 \mathrm{~nm}}=47 \mathrm{sr}$ and $S_{a, 1064 \mathrm{~nm}}=33 \mathrm{sr}$, matching the measured lidar ratios 


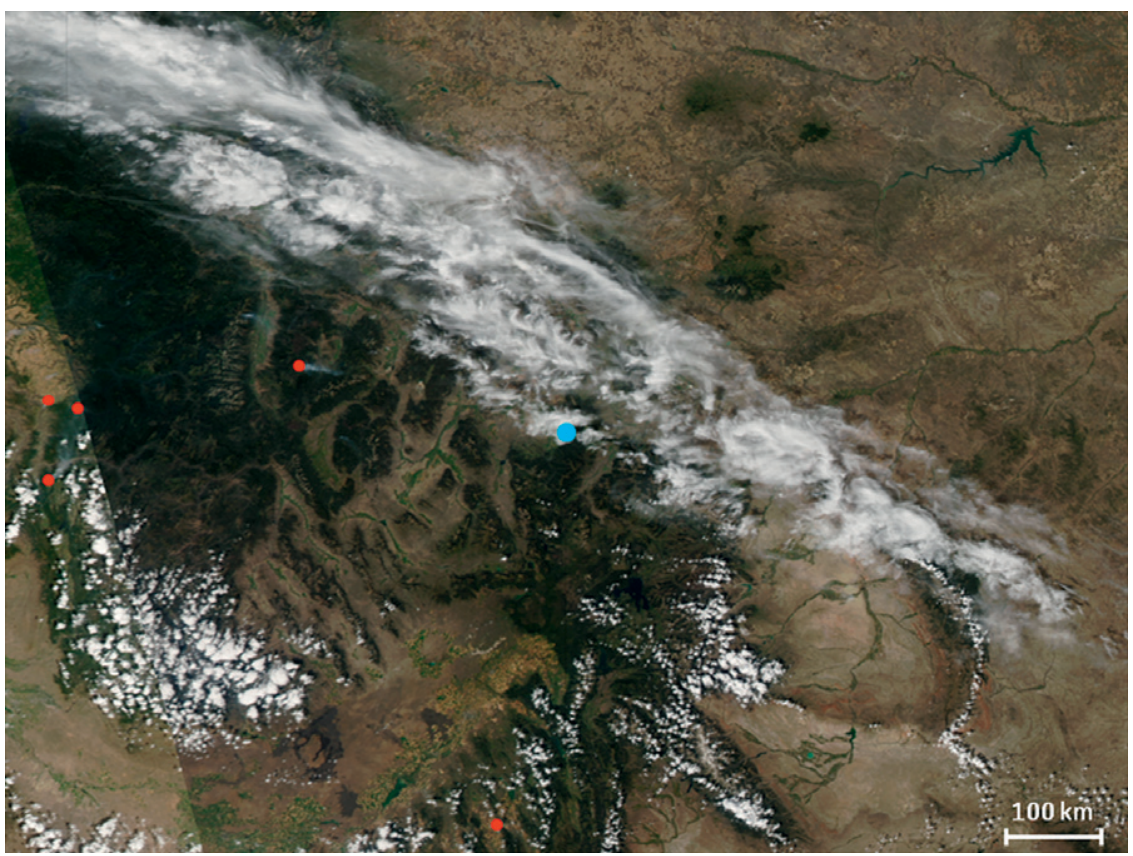

FIG. 14. A true-color satellite image from the MODIS instrument aboard the Aqua satellite. The granule overpass times were 1355 and 1521 MDT on 27 Aug 2009. Bozeman is indicated by the blue circle while fire activity is represented by the red dots.

inferred from the two-color lidar data collected in the afternoon. Using a linear combination of $33 \%$ smoke and $67 \%$ clean continental yields a fine- (coarse) mode fraction of $0.142(0.858)$ based on the aerosol models developed by Omar et al. The aerosol fine- (coarse) mode fraction by volume for data collected by the solar radiometer in the afternoon has a value of $0.0955 \pm 0.0064(0.9065 \pm$ 0.0028 ), which shows good agreement with the fine(coarse) mode fraction by volume of the combined aerosol types calculated from the Omar et al. models. The increase of the optical depth associated with the lofted aerosol layer seen in Fig. 8 at approximately $2 \mathrm{~km}$ is calculated to be $0.046(0.047,0.047)$ at $1500(1600,1700)$ MDT. The total aerosol optical depth at $1500(1600,1700)$ MDT was measured to be $0.147(0.151,0.153)$ at $1500(1600,1700)$ MDT. This results in an average contribution to the aerosol optical depth of $31 \%$. This is consistent with the linear combination of the aerosol models described above.

The lidar inversion using the aerosol optical depth as a constraint requires an assumption of a constant lidar ratio. However, as seen in Fig. 1, the stratification of various aerosol layers implies that the lidar ratio is not constant with height. For these unmixed layers, linear combinations of the model-based aerosol optical properties such as the lidar ratio may better match the measured column-averaged aerosol optical properties. These linear

TABLE 5. A list of selected retrieved aerosol optical properties used for comparison with the aerosol models developed by Catrall et al. (Reagan et al. 2004; Cattrall et al. 2005; Wang et al. 2005) and Omar et al. [Omar et al. (2005) and Omar et al. (2009)].

\begin{tabular}{|c|c|c|c|}
\hline \multicolumn{4}{|c|}{ Selected aerosol optical properties } \\
\hline Optical property & 0800-1100 MDT & 1500-1800 MDT & Instrument \\
\hline \multirow[t]{4}{*}{ Lidar ratio } & $S_{a, 532 \mathrm{~nm}}=61.2 \pm 6.7 \mathrm{sr}$ & $S_{a, 532 \mathrm{~nm}}=49.5 \pm 5.3 \mathrm{sr}$ & Solar radiometer \\
\hline & $S_{a, 1064 \mathrm{~nm}}=44.4 \pm 4.6 \mathrm{sr}$ & $S_{a, 1064 \mathrm{~nm}}=28.5 \pm 2.8 \mathrm{sr}$ & Solar radiometer \\
\hline & & $S_{a, 532 \mathrm{~nm}}=54.5 \pm 9.0 \mathrm{sr}$ & Two-color lidar \\
\hline & & $S_{a, 1064 \mathrm{~nm}}=31.7 \pm 3.7 \mathrm{sr}$ & Two-color lidar \\
\hline \multirow[t]{2}{*}{$\sigma_{532} / \sigma_{1064}$} & $2.70 \pm 0.18$ & $3.55 \pm 0.10$ & Solar radiometer \\
\hline & & $4.16 \pm 0.70$ & Two-color lidar \\
\hline$\beta_{532} / \beta_{1064}$ & & $2.28 \pm 0.35$ & Two-color lidar \\
\hline Fine-mode volume fraction & & $0.0955 \pm 0.0064$ & Solar radiometer \\
\hline Coarse-mode volume fraction & & $0.9065 \pm 0.0028$ & Solar radiometer \\
\hline
\end{tabular}


combinations of the aerosol optical properties must match for the aerosol optical properties at each wavelength presented in the aerosol optical model, providing a constraint on the possible linear combinations.

The aerosol optical properties measured between 1430 and 2300 MDT and summarized in Table 5 can be compared to the aerosol models developed by Cattrall et al. (Reagan et al. 2004; Cattrall et al. 2005; Wang et al. 2005), which are summarized in Table 4. For data collected in the afternoon with the two-color lidar, an $S_{a, 532 \mathrm{~nm}}=54.5 \mathrm{sr}$ and an $S_{a, 1064 \mathrm{~nm}}=28.5 \mathrm{sr}$ were inferred from the lidar inversion and comparison to the aerosol optical depth. Using these lidar ratios to complete the lidar inversion, the ratio of the aerosol backscatter of $\beta_{532} / \beta_{1064}=2.28 \pm 0.35$ and a ratio of the aerosol extinction of $\sigma_{532} / \sigma_{1064}=4.16 \pm$ 0.70 were calculated. Using a linear combination of $67 \%$ for rural continental and 33\% for smoke, the model developed by Catrall et al. predicts lidar ratios of $S_{a, 532 \mathrm{~nm}}=$ $52.6 \mathrm{sr}$ and $S_{a, 1064 \mathrm{~nm}}=30.3 \mathrm{sr}$, a ratio of the aerosol backscatter of $\beta_{532} / \beta_{1064}=1.7 \pm 0.3$, and a ratio of the aerosol extinction of $\sigma_{532} / \sigma_{1064}=3.3 \pm 0.5$.

\section{b. Radiative forcing}

The change in the radiative forcing resulting from the intrusion of the smoke can be estimated in the following manner. The mean shortwave radiative forcing resulting from the aerosol direct effect can be written as (Charlson et al. 1992)

$$
\Delta F_{R}=-\frac{1}{4} F_{T}\left(1-A_{c}\right) \Delta R_{a},
$$

where $(1 / 4) F_{T}$ is the global mean top-of-the-atmosphere radiative flux, $A_{c}$ is the fractional cloud cover, and $\Delta R_{a}$ is the perturbation of the planetary mean albedo resulting from the atmospheric aerosols, which can be written as (Charlson et al. 1992)

$$
\Delta R_{a}=2 T^{2}\left(1-R_{s}\right)^{2} \beta_{f} \delta_{a},
$$

where $T$ is the fraction of light transmitted by the atmosphere above the aerosol layer, $R_{S}$ is the mean albedo of the underlying surface, $\beta$ is the fraction of incident light scattered upward by the aerosol layer of interest, and $\delta_{a}$ is the aerosol optical depth for the aerosol layer of interest. Assuming a constant lidar ratio, the aerosol optical depth can be written

$$
\delta_{a}=e^{-S_{a, \lambda} \int_{r_{1}}^{r_{2}} \beta_{a}(r, \lambda) d r},
$$

where $\beta_{a}(r, \lambda)$ is the aerosol backscatter coefficient, $\mathrm{r}_{1}$ is the range to the bottom of the aerosol layer, and $\mathrm{r}_{2}$ is the range to the top of the aerosol layer. With the assumption that most of the aerosols are contained within the planetary boundary layer, the fraction of incident light scattered upward by the aerosols can be written as

$$
\beta_{f}=\int_{0}^{r_{\mathrm{PBL}}} \beta(r, \lambda) d r,
$$

where $r_{\mathrm{PBL}}$ is the range to the top of the planetary boundary layer. Using Eqs. (1)-(4), the mean shortwave radiative forcing associated with the aerosol direct effect for the aerosols contained within the planetary boundary layer can be written as

$$
\Delta F_{R}=-\frac{1}{2} F_{T}\left(1-A_{c}\right)\left(1-R_{s}\right) T^{2} \frac{\delta_{a}}{S_{a}} \ln \left(\frac{1}{\delta_{\mathrm{a}}}\right) .
$$

Assuming that the global mean top-of-the-atmosphere radiative flux, fraction cloud cover, surface albedo, and fraction of light transmitted above the aerosol layer of interest remain constant, the ratio of the radiative forcing resulting from the aerosol direct effect at two different times can be written as

$$
\frac{\Delta F_{R, 2}}{\Delta F_{R, 1}}=\frac{S_{a, 1}}{S_{a, 2}} \frac{\delta_{a, 2}}{\delta_{a, 1}} \frac{\ln \left(\delta_{a, 2}\right)}{\ln \left(\delta_{a, 1}\right)} .
$$

During the morning of 28 August 2009, the aerosol optical depth averaged between 0800 and 1000 MDT (1500 and $1800 \mathrm{MDT})$ at $532 \mathrm{~nm}$ was $\delta_{\alpha, 1}=0.07804 \pm 0.00751$ $\left(\delta_{\alpha, 2}=0.1512 \pm 0.0132\right)$ and the corresponding lidar ratio was $S_{a, 1}=61.2 \pm 6.7 \mathrm{sr}\left(S_{a, 2}=49.5 \pm 5.3 \mathrm{sr}\right)$. Using these results, the ratio of the radiative forcing resulting from the aerosol direct effect between 1500 and 1800 MDT is a factor of $1.8 \pm 0.5$ larger than the radiative forcing resulting from the aerosol direct effect between 0800 and 1000 MDT.

\section{Concluding remarks}

Data from a collocated two-color lidar, a diode laser based water vapor DIAL, a solar radiometer, and a ground-based nephelometer of instruments were used to characterize the aerosol optical properties under dry conditions with a relative humidity below $60 \%$. The lidar ratios for the aerosols measured using the twocolor lidar were $S_{a, 532 \mathrm{~nm}}=54.5 \pm 9.0 \mathrm{sr}$ for the $532-\mathrm{nm}$ channel and $S_{a, 1064 \mathrm{~nm}}=28.5 \pm 2.8 \mathrm{sr}$ for the $1064-\mathrm{nm}$ channel. The lidar ratios measured using the solar radiometer were $S_{a, 532 \mathrm{~nm}}=49.5 \pm 5.3 \mathrm{sr}$ for the $532-\mathrm{nm}$ wavelength and $S_{a, 1064 \mathrm{~nm}}=31.6 \pm 3.7 \mathrm{sr}$ the $1064-\mathrm{nm}$ wavelength. The scattering component of the aerosol extinction measured at $550 \mathrm{~nm}$ using the nephelometer 
was $2.35 \times 10^{-5} \pm 0.20 \times 10^{-5} \mathrm{~m}^{-1}$ while the scattering component of the aerosol extinction measured using the two-color lidar and solar radiometer was $2.30 \times 10^{-5} \pm$ $0.61 \times 10^{-5} \mathrm{~m}^{-1}$. The agreement of these various measurements shows consistent measurements of aerosol optical properties from the multiple instruments, indicating a successful closure experiment.

The collocated two-color lidar, diode-laser-based water vapor differential absorption lidar (DIAL), solar radiometer, and ground-based nephelometer allowed the aerosol optical properties to be inferred from the collected data. These aerosol optical properties were then used in conjunction with aerosol models to determine that a thin layer of smoke was present. This conclusion is consistent with back-trajectory analysis showing that the air mass over Bozeman, Montana, on 28 August originated from areas where forest fires were burning. The aerosol optical properties were used to estimate the change in the radiative forcing resulting from the aerosol direct effect to be $1.8 \pm 0.5$.

The long-term monitoring of atmospheric aerosols under ambient atmospheric conditions needs to occur on the local to regional scales due to the nonuniform aerosol spatial distribution from a wide variety of geographic locations to encompass the diversity of aerosol species. The deployment of this initial set of instruments represents the first step in the development of a small-scale remote sensing facility for atmospheric studies at Montana State University. The goal of the remote sensing facility for atmospheric studies is to develop a set of coordinated instruments for long-term observation studies of atmospheric aerosols from a rural continental site.

Acknowledgments. This work was kindly supported under the auspices of a NASA EPSCoR grant (NNX08AT69A) and the NASA Graduate Student Researchers Program.

\section{REFERENCES}

Ackerman, T., and G. Stokes, 2003: The Atmospheric Radiation Measurement Program. Phys. Today, 56, 38-45, doi:10.1063/ 1.1554135 .

Andrews, E., P. J. Sheridan, J. A. Ogren, and R. Farrare, 2004: In situ aerosol profiles over the Southern Great Plains cloud and radiation test bed site: 1 . Aerosol optical properties. J. Geophys. Res., 109, D06208, doi:10.1029/2003JD004025.

Browell, E. V., S. Ismail, and B. E. Grossman, 1991: Temperature sensitivity of differential absorption lidar measurements of water vapor in the $720 \mathrm{~nm}$ region. Appl. Opt., 30, 1517-1524.

Cattrall, C., J. Reagan, K. Thome, and O. Dubovik, 2005: Variability of aerosol and spectral lidar and backscatter and extinction ratios for key aerosol types derived from selected Aerosol Robotic Network locations. J. Geophys. Res., 110, D10S11, doi:10.1029/ 2004JD005124.
Charlson, R. J., S. E. Schwartz, J. M. Hales, R. D. Cess, J. A. Coakley Jr., J. E. Hansen, and D. J. Hofmann, 1992: Climate forcing by anthropogenic aerosols. Science, 2565, 423-430.

Delle Monache, L., K. D. Perry, R. T. Cederwall, and J. A. Ogren, 2004: In situ aerosol profiles over the Southern Great Plains Cloud and Radiation Testbed site: 2. Effects of mixing height on aerosol properties. J. Geophys. Res., 109, D06209, doi:10.1029/ 2003JD004024.

Eck, T. F., B. N. Holben, J. S. Reid, O. Dubovik, A. Smirnov, N. T. O’Neill, I. Slutsker, and S. Kinne, 1999: Wavelength dependence of the aerosol optical depth of biomass burning, urban, and desert dust aerosols. J. Geophys. Res., 104, 31 33331349.

Fernald, F. G., 1984: Analysis of atmospheric lidar applications: Some comments. Appl. Opt., 23, 652-653.

— B. M. Herman, and J. A. Reagan, 1972: Determination of aerosol height distributions by lidar. J. Appl. Meteor., 11, 482-489.

Ferrare, R., and Coauthors, 2000: Comparison of aerosol optical properties and water vapor among ground and airborne lidars and sun photometers during TARFOX.J. Geophys. Res., 105, 9917-9933.

, G. Feingold, S. Ghan, J. Ogren, B. Schmid, S. E. Schwartz, and P. Sheridan, 2006: Preface to special section: Atmospheric Radiation Measurement Program May 2003 Intensive Operation Period examining aerosol properties and radiative influences. J. Geophys. Res., 111, D05S01, doi:10.1029/205JD006908.

Forster, P., and Coauthors, 2007: Changes in atmospheric constituents and in radiative forcing. Climate Change 2007: The Physical Science Basis, S. Solomon et al., Eds., Cambridge University Press, 129-234.

Haywood, J., and O. Boucher, 2000: Estimates of the direct and indirect radiative forcing due to tropospheric aerosols: A review. Rev. Geophys., 38, 513-545.

, P. Francis, O. Dubovik, M. Glew, and B. Holben, 2003: Comparison of aerosol size distributions, radiative properties, and optical depths determined by aircraft observations and sun photometers during SAFARI 2000. J. Geophys. Res., 108, 8471, doi:10.1029/2002JD002250.

Holben, B. N., and Coauthors, 2001: An emerging ground-based aerosol climatology: Aerosol optical depth from AERONET. J. Geophys. Res., 106, 12 067-12 097.

Huebert, B. J., T. Bates, P. B. Russell, G. Shi, Y. J. Kin, K. Kawamura, G. Carmichael, and T. Nakajima, 2003: An overview of ACE-Asia: Strategies for quantifying the relationships between Asian aerosols and their climate impacts. J. Geophys. Res., 108, 8633, doi:10.1029/2003JD003550.

Ismail, S., E. V. Browell, R. A. Farrare, S. A. Kooi, M. B. Clayton, V. G. Brackett, and P. B. Russell, 2000: LASE measurements of aerosol and water vapor profiles during TARFOX. J. Geophys. Res., 105, 9903-9916.

Johnson, B. T., S. Christopher, J. M. Haywood, S. R. Osborne, S. MacFarlane, C. Hsu, C. Salustro, and R. Kahn, 2009: Measurements of aerosol optical properties from aircraft, satellite, and ground-based remote sensing: A case study from the Dust and Biomass-burning Experiment (DABEX). Quart. J. Roy. Meteor. Soc., 135, 922-934.

Kotchenruther, R. A., P. V. Hobbs, and D. A. Hegg, 1999: Humidification factors for atmospheric aerosols off the mid-Atlantic coast of the United States. J. Geophys. Res., 104, 2239-2251.

Kovalev, V. A., and W. E. Eichinger, 2004: Elastic Lidar: Theory, Practice, and Analysis Methods. John Wiley and Sons, $615 \mathrm{pp}$ 
Machol, J. L., and Coauthors, 2004: Preliminary measurements with an automated compact differential absorption lidar for the profiling of water vapor. Appl. Opt., 43, 3110-3121.

McPherson, C. J., and J. A. Reagan, 2010: Analysis of optical properties of Saharan dust derived from dual-wavelength aerosol retrievals from CALIPSO observations. IEEE Geosci. Remote Sens. Lett., 7, 98-102.

, — , J. Schafer, D. Giles, R. Ferrare, J. Hair, and C. Hostetler, 2010: AERONET, Airborne HSRL, and CALIPSO retrievals compared and combined: A case study. J. Geophys. Res., 115, D00H21, doi:10.1029/2009JD012389.

Nehrir, A. R., K. S. Repasky, and J. L. Carlsten, 2009a: Design and testing of a compact diode-laser-based differential absorption lidar (DIAL) for water vapor profiling in the lower troposphere. Lidar Remote Sensing for Environmental Monitoring X, U. N. Singh, Ed., International Society for Optical Engineering, (SPIE Proceedings, Vol. 7460), doi:10.1117/12.824900.

,,--- M. D. Obland, and J. A. Shaw, 2009b: Water vapor profiling using a widely tunable, amplified diode laser based Differential Absorption Lidar (DIAL). J. Atmos. Oceanic Technol., 26, 733-745.

Omar, A. H., J. Won, D. M. Winker, S. Yoon, O. Dubovik, and M. P. McCormick, 2005: Development of global aerosol models using cluster analysis of Aerosol Robotic Network (AERONET) measurements. J. Geophys. Res., 110, D10S14, doi:10.1029/2004JD004874.

, and Coauthors, 2009: The CALIPSO automated aerosol classification and lidar ratio selection algorithm. J. Atmos. Oceanic Technol., 26, 1994-2014.

Pahlow, M., D. Muller, M. Tesche, H. Eichler, G. Feingold, W. L. Eberhard, and Y. Cheng, 2006: Retrieval of aerosol properties from combined multiwavelength lidar and sunphotometer measurements. Appl. Opt., 45, 7429-7442.

Reagan, J. A., X. Wang, and M. T. Osborn, 2002: Spaceborne lidar calibration from cirrus and molecular backscatter returns. IEEE Trans. Geosci. Remote Sens., 40, 2285-2290.

_ - C C. Cattrall, and K. Thome, 2004: Spaceborne lidar aerosol retrieval approaches based on aerosol model Constraints. Proc. Int. Geoscience and Remote Sensing Symp. (IGARSS'04), Anchorage, AK, IEEE, 1940-1943.
$\_,-$, S. Palm, and J. Spinhirne, 2006: Lidar aerosol retrievals from Icesat using a model based constrained ratio approach. Preprints, 12th Conf. on Atmospheric Radiation, Madison, WI, Amer. Meteor. Soc., 8.1. [Available online at http://ams. confex.com/ams/pdfpapers/113152.pdf.]

- C. J. McPherson, C. A. Hostetler, J. W. Hair, and R. A. Ferrare, 2007: Initial CRAM aerosol retrievals from CALIPSO and supporting airborne HSRL measurements. Proc. Int. Geoscience and Remote Sensing Symp. (IGARSS'07), Barcelona, Spain, IEEE, 4979-4982.

Schmid, B., and Coauthors, 2003: Column closure studies of lowertropospheric aerosols and water vapor during ACE-Asia using airborne sun photometer and airborne in situ and ship-based lidar measurements. J. Geophys. Res., 108, 8656, doi:10.1029/ 2002JD003361.

—_ and Coauthors, 2006: How well do state-of-the-art techniques measuring the vertical profile of tropospheric aerosol extinction compare? J. Geophys. Res., 111, D05S07, doi:10.1029/ 2005JD005837.

— , and Coauthors, 2009: Validation of aerosol extinction and water vapor profiles from routine Atmospheric Radiation Measurement Program Climate Research Facility measurements. J. Geophys. Res., 114, D22207, doi:10.1029/2009JD012682.

Sheridan, P. J., D. J. Delene, and J. A. Ogren, 2001: Four years of continuous surface aerosol measurements from the Department of Energy's Atmospheric Radiation Measurement Program Southern Great Plains Cloud and Radiation Testbed site. J. Geophys. Res., 106, 20 735-20 747.

Stokes, G. M., and S. E. Schwartz, 1994: The Atmospheric Radiation Measurement (ARM) Program: Programmatic background and design of the cloud and radiation testbed. Bull. Amer. Meteor. Soc., 75, 1201-1221.

Wang, X., J. Reagan, C. Cattrall, and K. Thome, 2005: Spaceborne lidar aerosol retrieval approaches based on improved aerosol model constraints. Proc. IEEE Workshop on Remote Sensing of Atmospheric Aerosols, Tuscon, AZ, IEEE, 36-42.

Wulfmeyer, V., and G. Feingold, 2000: On the relationship between relative humidity and particle backscatter coefficient in the marine boundary layer determined with differential absorption lidar. J. Geophys. Res., 105, 4729-4741. 